Journal Club

Editor's Note: These short reviews of a recent paper in the Journal, written exclusively by graduate students or postdoctoral fellows, are intended to mimic the journal clubs that exist in your own departments or institutions. For more information on the format and purpose of the Journal Club, please see http://www.jneurosci.org/misc/ifa_features.shtml.

\title{
Molecular Layer Interneurons Relay Cerebellar Cortical Activity to Bergmann Glial Cells
}

\author{
Tycho M. Hoogland, Eugene F. Civillico, and Bernd Kuhn \\ Department of Molecular Biology, Program in Neuroscience, Princeton University, Princeton, New Jersey 08544 \\ Review of Piet and Jahr (http://www.jneurosci.org/cgi/content/full/27/15/4027)
}

Astrocytes are increasingly viewed as active participants in the moment-tomoment functioning of the brain. They respond to neural activity (Beierlein and Regehr, 2006), affect network excitability (Pascual et al., 2005), and regulate blood flow (Takano et al., 2006). One structurally elaborate astrocyte, the Bergmann glial cell (BG) of the cerebellum, is in an ideal position to take part in all these functions. BG processes extend vertically through the cerebellar cortex and contact numerous elements of the cerebellar cortical circuitry, as well as blood vessels (Castejón et al., 2002), putting them in a position to both respond to and influence cerebellar processing and blood flow.

A recent report in The Journal of $\mathrm{Neu}$ roscience (Piet and Jahr, 2007) confirms and extends observations linking neural activity to calcium elevations in BGs. The role of parallel fiber (PF) activity in causing such elevations has been established before (Beierlein and Regehr, 2006). The novelty here is the proposed role of molecular layer (ML) interneurons in relaying PF activity to BGs (Fig. 1). The authors suggest that glutamate spillover during burst stimulation of the PF pathway activates metabotropic glutamate receptors

Received Aug. 8, 2007; revised Aug. 24, 2007; accepted Aug. 24, 2007. Correspondence should be addressed to Dr. Tycho M. Hoogland, Department of Molecular Biology, Lewis Thomas Laboratory, Princeton University, Washington Road, Princeton, NJ 08544. E-mail: hoogland@princeton.edu.

DOI:10.1523/JNEUROSCI.3597-07.2007

Copyright $\odot 2007$ Society for Neuroscience $\quad$ 0270-6474/07/2711167-03\$15.00/0
(mGluRs) on ML interneurons. This in turn would lead to corelease of ATP with GABA. The authors propose that the synaptically released ATP activates $\mathrm{P} 2$ receptors on BGs, causing calcium release from internal stores.

Working in slices from juvenile rats, Piet and Jahr (2007) used a photodiode to record BG calcium transients, while recording BG whole-cell currents with a patch electrode. Calcium changes were reported by the fluorescent calcium indicator Fluo-5F delivered through the patch pipette. Electrical stimulation of the $\mathrm{PF}$ pathway in the ML (10 stimuli at $100 \mathrm{~Hz}$ ) caused two-phase calcium elevations in BGs and concomitant inward currents measured at the BG cell bodies [Piet and Jahr (2007), their Fig. 1Aa (http://www. jneurosci.org/cgi/content/full/27/15/ 4027/F1)]. The first phase peaked rapidly (150-200 ms after onset of the stimulus) and was small in amplitude; the second phase peaked at $\sim 3$ s after stimulation and was of larger amplitude and duration [Piet and Jahr (2007), their Fig. $1 \mathrm{Ab}$ (http://www.jneurosci.org/cgi/content/ full/27/15/4027/F1)]. The first phase was blocked together with the whole-cell BG current by the AMPA receptor (AMPAR) antagonist 2,3-dihydroxy-6-nitro-7-sulfonyl-benzo[f]quinoxaline (NBQX) [Piet and Jahr (2007), their Fig. $1 B a, B b$ (http:// www.jneurosci.org/cgi/content/full/27/ $15 / 4027 / F 1)]$. This supports the idea that during strong PF activity, glutamate spill- over activates calcium-permeable AMPARs on BGs.

During burst stimulation of PFs large calcium elevations have been observed in BGs that are sensitive to blockers of internal calcium stores (Beierlein and Regehr, 2006). In the present study, cyclopiazonic acid, a calcium store pump blocker, abolished the second-phase calcium elevations [Piet and Jahr (2007), their Fig. 2Aa,Ab (http://www.jneurosci.org/cgi/content/ full/27/15/4027/F2)]. In a finding corroborating the previous Beierlein and Regehr (2006) study, P2 purinergic receptor antagonists [pyridoxal-phosphate-6-azophenyl-2', $4^{\prime}$-disulfonic acid (PPADS) and reactive blue-2] diminished the $B G$ signal, suggesting that these receptors are activated during PF stimulation and trigger store release [Piet and Jahr (2007), their Fig. $2 \mathrm{Ba}$ (http://www.jneurosci.org/ cgi/content/full/27/15/4027/F2)]. Pressure application of exogenous ATP in the presence of TTX to block neural activity triggered a BG calcium elevation similar to that seen during PF stimulation and was also blocked by PPADS. Thus P2 receptors are likely activated directly on BGs [Piet and Jahr (2007), their Fig. 2 Bb (http://www.jneurosci.org/cgi/content/ full/27/15/4027/F2)]

A distinguishing feature in the current study was that stimulation close to the BGs $(20-30 \mu \mathrm{m})$ caused calcium elevations that were insensitive to the mGluR antagonist 7-(hydroxy-imino) cyclopropachromen-1a-carboxylate ethyl ester 
(CPCCOet), whereas an mGluR antagonist-sensitive response was seen when PFs were stimulated 100-250 $\mu \mathrm{m}$ from the recorded BGs in transverse slices [Piet and Jahr (2007), their Fig. $4 A b$ (http://www.jneurosci.org/cgi/content/ full/27/15/4027/F4)]. The authors propose that stimulation of cells close to the stimulation electrode could have bypassed upstream activation of mGluRs. Interestingly, coapplication of CPCCOet and PPADS did not reduce the BG signals more than CPCCOet alone [Piet and Jahr (2007), their Fig. $4 B a, B b$ (http://www. jneurosci.org/cgi/content/full/27/15/ 4027/F4)], ruling out parallel pathways. Combined with the finding that the second-phase BG signal during local stimulation was dependent on the $\mathrm{P} 2$ receptor, but insensitive to mGluR activation [Piet and Jahr (2007), their Fig. 4Ca,Cb (http:// www.jneurosci.org/cgi/content/full/27/ $15 / 4027 / F 4)]$, these data suggest that mGluR activation occurred in a cellular structure upstream of $\mathrm{P} 2$ receptor activation, which subsequently releases ATP.

To establish the predominant source of ATP during PF activation, the authors examined the second-phase BG signal in the presence of TTX to block neural activity [Piet and Jahr (2007), their Fig. 5A (http://www.jneurosci.org/cgi/content/ full/27/15/4027/F5)]. The signal was abolished, indicating a neuronal source for ATP release. The authors considered several possible neuronal sources of ATP release. They reasoned that PFs could be eliminated because of their lack of mGluR receptors. Neither single nor burst stimulation of climbing fibers (CFs) was able to evoke the typical BG calcium response seen during ML stimulation of PFs. In the same experiments, the BG signals could be recovered by repositioning the stimulating electrode in the ML, indicating that the circuitry remained uncompromised [Piet and Jahr (2007), their Fig. 5B (http:// www.jneurosci.org/cgi/content/full/27/ 15/4027/F5)]. These results were used to eliminate ATP release from Purkinje cells (PCs). However, this conclusion relies on the assumption that burst stimulation of the CF and PF pathways are functionally comparable with regard to their effects on PCs. It is conceivable that PF stimulation might cause ATP release from PCs even if CF stimulation does not.

ML interneurons as a source of ATP were investigated next. The authors measured the effects of their PF stimulation protocol on ML interneurons indirectly, by recording inhibitory synaptic currents from PCs. In PCs clamped at $0 \mathrm{mV}$, late-

\section{synaptically released ATP}

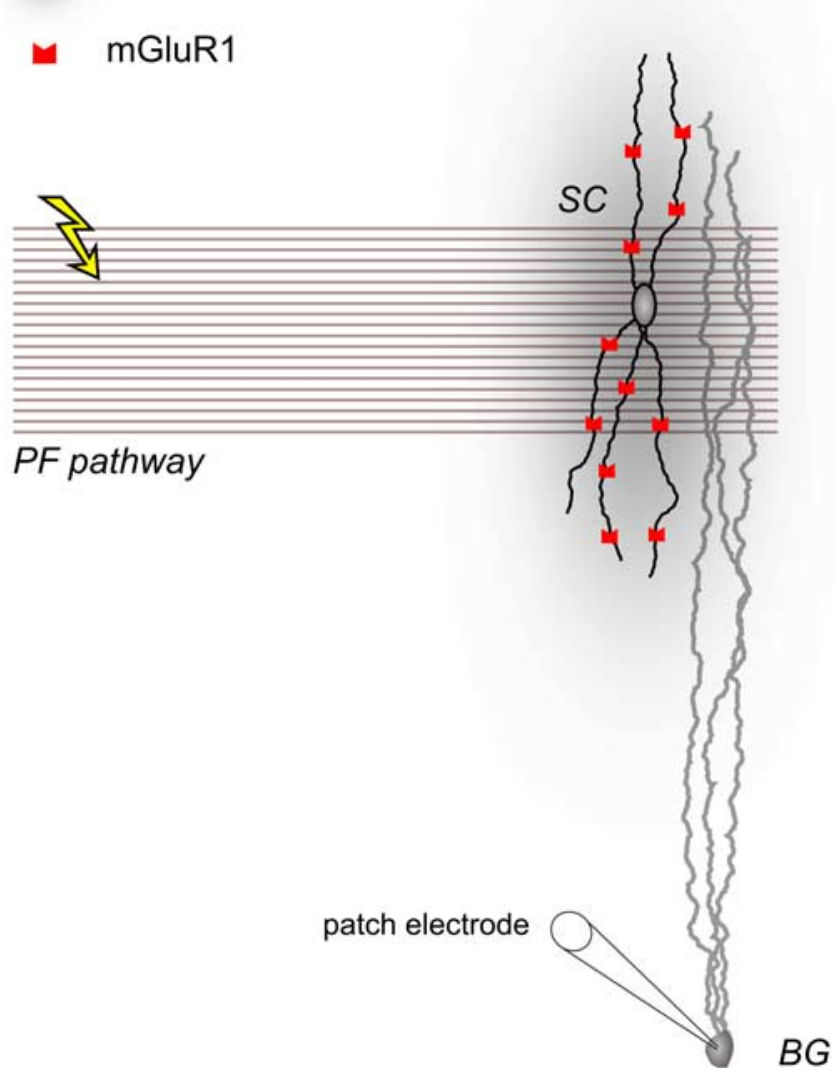

Figure 1. From parallel fiber activity to Bergmann glial cell function. Electrical stimulation of the parallel fiber pathway results in NBQX-sensitive inward currents, also detectable optically as small and fast calcium transients, in BGs. Additionally, activation of mGluR1 on molecular layer interneurons, such as the stellate cell (SC) depicted, can result in the synaptic release of ATP, triggering $P 2$ receptor-mediated calcium release from stores in BGs.

onset, slow outward currents were evoked in the presence of the ionotropic glutamate receptor blockers NBQX and 3-(R-2-carboxypiperazin-4-yl)-propyl-1phosphonic acid [Piet and Jahr (2007), their Fig. $6 A$ (http://www.jneurosci.org/ cgi/content/full/27/15/4027/F6)]. PC currents were sensitive to gabazine, a $\mathrm{GABA}_{\mathrm{A}}$ receptor blocker [Piet and Jahr (2007), their Fig. $6 B$ (http://www.jneurosci.org/ cgi/content/full/27/15/4027/F6)]. These results support a mechanism in which $\mathrm{PF}$ activity activates mGluRs on ML interneurons, which then provide GABAergic input to PCs. Additional experiments in which mGluR1 was blocked showed a reduced charge transfer in PCs [Piet and Jahr (2007), their Fig. 6C (http://www. jneurosci.org/cgi/content/full/27/15/ 4027/F6)]. Interestingly, the data show that small spontaneous IPSCs from interneurons were preserved, but the slow response mediated through the mGluR mechanism was abolished.

These results tantalizingly suggest that ML interneurons relay strong PF activity to BGs. The importance of ML interneurons in this pathway might have been further clarified by simultaneous whole-cell recordings from these cells and BGs. Cell type specificity could have been inferred (e.g., stellate cells vs basket cells). Furthermore, such experiments would also allow direct comparison of the time course of $\mathrm{mGluR}$ receptor currents in interneurons with the slow BG signals. Finally, it would have been possible to determine the postsynaptic effect on ML interneurons of the burst PF stimulation. Stimulating the cells directly should result in BG activation and would circumvent the need for extended pharmacology and indirect measurements from PCs.

It would be of great interest to establish the conditions required to replicate these results in vivo. Spontaneously occurring beams of PF activity have not been reported (Sullivan et al., 2005). Thus, the activity patterns required to activate ML interneurons sufficiently to trigger the observed BG signals still need to be uncovered.

Another open question is the func- 
tional relevance of purinergic signaling between interneurons and BGs. A recent study by Rancillac et al. (2006) may provide an answer. Their findings support the idea that PCs and ML interneurons have opposing roles in regulating blood vessel diameter, with activity in PCs linked to vasoconstriction and activity in interneurons to vasodilation. Blood vessel diameter changes have been reported in vivo during calcium elevations in astrocytes (Takano et al., 2006). BGs come in close contact with blood vessels (based on our own observations) and may be responsible for regulating cerebellar blood flow. It seems reasonable to assume then that changes in excitability can activate astrocytes either directly or indirectly and in turn modulate blood flow to meet metabolic demands. This study nicely demonstrates neural mechanisms that could trigger BG responses under normal conditions. We anticipate that future studies, particularly in vivo, may provide insight into the more specific requirements for these responses, as well as their consequences.

\section{References}

Beierlein M, Regehr WG (2006) Brief bursts of parallel fiber activity trigger calcium signals in Bergmann glia. J Neurosci 26:6958-6967.

Castejón OJ, Dailey ME, Apkarian RP, Castejón HV (2002) Correlative microscopy of cerebellar Bergmann glial cells. J Submicrosc $\mathrm{Cy}-$ tol Pathol 34:131-142.

Pascual O, Casper, KB, Kubera C, Zhang J,
Revilla-Sanchez R, Sul J, Takano H, Moss SJ, McCarthy K, Haydon, PG (2005) Astrocytic purinergic signaling coordinates synaptic networks. Science 310:113-116.

Piet R, Jahr CE (2007) Glutamatergic and purinergic receptor-mediated calcium transients in Bergmann glial cells. J Neurosci 27:4027-4035.

Rancillac A, Rossier J, Guille M, Tong X, Geoffroy H, Amatore C, Arbault S, Hamel E, Cauli B (2006) Glutamatergic control of microvascular tone by distinct GABA neurons in the cerebellum. J Neurosci 26:6997-7006.

Sullivan MR, Nimmerjahn A, Sarkisov DV, Helmchen F, Wang SS (2005) In vivo calcium imaging of circuit activity in cerebellar cortex. J Neurophysiol 94:1636-1644.

Takano T, Tian G, Peng W, Lou N, Libionka W, Han X, Nedergaard M (2006) Astrocytemediated control of cerebral blood flow. Nat Neurosci 9:260-267. 